\begin{tabular}{|c|c|c|c|c|c|c|}
\hline \multirow{4}{*}{ Impact Factor: } & ISRA (India) & $=3.117$ & SIS (USA) & $=0.912$ & ICV (Poland) & $=6.630$ \\
\hline & ISI (Dubai, UAE & $=0.829$ & РИНЦ (Russia) & $=0.156$ & PIF (India) & $=1.940$ \\
\hline & GIF (Australia) & $=0.564$ & ESJI (KZ) & $=\mathbf{5 . 0 1 5}$ & IBI (India) & $=4.260$ \\
\hline & JIF & $=1.500$ & SJIF (Morocco) & $=5.667$ & OAJI (USA) & $=0.350$ \\
\hline
\end{tabular}

\begin{tabular}{|c|c|}
\hline $\begin{array}{l}\text { SOI: } \underline{1.1 /} \\
\text { International S } \\
\text { Theoretical } \mathbb{\&}\end{array}$ & $\begin{array}{l}\text { AS } \text { DOI: } 10.15863 / \text { TAS } \\
\text { cientific Journal }\end{array}$ \\
\hline p-ISSN: 2308-4944 (print) & e-ISSN: 2409-0085 (online) \\
\hline Year: 2019 Issue: 01 & Volume: 69 \\
\hline Published: 23.01.2019 & http://T-Science.org \\
\hline
\end{tabular}

QR - Issue

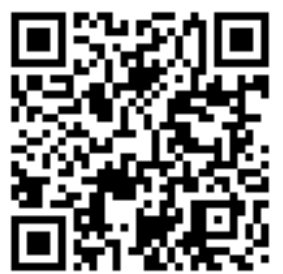

QR - Article

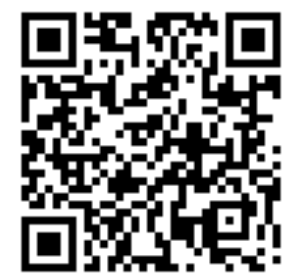

Anar Bahtiyarovich Gasimov graduate student of the National Academy of Sciences of Kyrgyz Republic

SECTION 32. Jurisprudence.

\title{
THE CONCEPT AND PRINCIPLES OF TAX CONTROL, ITS PLACE IN THE FINANCIAL CONTROL SYSTEM
}

Abstract: The author in this article considers tax control as part of financial control. At the same time, the state, through legislative regulation of the system of relations between authorized bodies and the taxpayer (as well as other obliged persons), should ensure a certain balance of public and private interest, taking into account constitutional restrictions on interference with the subject of tax legal relations in a market economy. He notes that the need for a tax control system, as well as a general view, reflects the legal basis for its construction.

Key words: tax control, financial control, policy, authorized law, economy, declaration, offense, liability.

Language: Russian

Citation: Gasimov, A. B. (2019). The concept and principles of tax control, its place in the financial control system. ISJ Theoretical \& Applied Science, 01 (69), 187-190.

Soi: http://s-o-i.org/1.1/TAS-01-69-24 Doi: rossef https://dx.doi.org/10.15863/TAS.2019.01.69.24

\section{ПОНЯТИЕ И ПРИНЦИПЫ НАЛОГОВОГО КОНТРОЛЯ, ЕГО МЕСТО В СИСТЕМЕ ФИНАНСОВОГО КОНТРОЛЯ}

Аннотация: Автор в данной статье рассматривает налогового контроля как часть финансового контроля. При этом государство путем законодательного регулирования системы взаимоотношений уполномоченных органов и налогоплательщика (а также иных обязанных лии) должно обеспечить определенный баланс публичного и частного интереса, учитывая конституционные ограничения на вмешательство в экономическую деятельность субъекта налоговых правоотночений в условиях рыночной экономики. Он отмечает, что необходимость существования системы налогового контроля, а такюе в общем виде отражается юридическая основа ее построения.

Ключевые слова: налоговый контроль, финансовый контроль, политика, уполномоченное право, экономика, декларация, правонарушение, ответственность.

\section{Introduction}

Налоговый контроль является элементом финансового контроля и частью налогового механизма. Налоговое контрольное действие охватывается всей системой налогообложения, а также осуществляется в разрезе отдельного налога, налоговой группы, группы налогоплательщиков, территория [1, с.365]. Налоговый контроль пронизывается всей экономикой и обеспечивается соблюдением правила бухгалтерских учетов и отчетности, законодательной основы налогообложения. Появлением налогового контроля вызваны объективные причины.

Налогоплательщики, обладают определенными имуществами на правах собственности или иных вещных прав, и всегда стремятся защищать свои частные имущественные интересы от налогового изъятия. Вместе с тем желания налогоплательщиков уменьшить размеры налогового платежа затрагивают имущественные интересы и другие стороны налогового отношения-государства.

В данной ситуации государство, защищает публичный интерес в налоговом отношении, вынужденно вырабатывает специальные механизмы собственного взаимодействия с конкретными налогоплательщиками или обязанными лицами, которые будут в итоге обеспечивать надлежащие поведения всех лиц для исполнения ими обязанностей по уплате налога и сбора и иного обязательства, предусмотренной налоговым законодательством. 


\begin{tabular}{|c|c|c|c|c|c|c|}
\hline \multirow{4}{*}{ Impact Factor: } & ISRA (India) & $=3.117$ & SIS (USA) & $=0.912$ & ICV (Poland) & $=6.630$ \\
\hline & ISI (Dubai, UAE & $=0.829$ & РИНЦ (Russia & $=0.156$ & PIF (India) & $=1.940$ \\
\hline & GIF (Australia) & $=0.564$ & ESJI (KZ) & $=5.015$ & IBI (India) & $=4.260$ \\
\hline & JIF & $=1.500$ & SJIF (Morocco & $=5.667$ & OAJI (USA) & $=0.350$ \\
\hline
\end{tabular}

Ясно, что охрана своего имущественного интереса в налоговой среде требует от государства, во-первых, создания специального государственного органа или органа и наделения их соответствующим властным полномочием по отношению к лицу, обязанного уплачивать налог и сбор. Во-вторых, важно на законодательном уровне установление порядка, форм и методов реализации деятельности созданного уполномоченного органа, а также видов воздействия данного органа на поведения обязанного лица, обеспечивающее в совокупности надлежащие поведения налогоплательщика и поступление налогового платежа в государственный бюджет.

Кроме этого, государство посредством законодательного контроля систем взаимоотношения уполномоченного органа и налогоплательщиков (а также иного обязанного лица) обязано обеспечивать определенный баланс публичных и частных интересов, с учетом конституционных ограничений по вмешательству в экономическую сферу субъектов налогового правоотношения.

Таким образом, из сказанного вытекают необходимость реализации систем налогового регулирования, а также в общем виде отражаются юридические основы ее строения. Важность налогового контроля еще может определятся наличием постоянного уклонения плательщика от налогообложений. Эти явления развивались параллельно с самими налогообложениями и приобрели формы устойчивых закономерностей. Существуют много способов уходов от налога посредством осуществлений определенной операции на фондовых рынках. В конце концов государства недополучают порой весьма значительную сумму налогового платежа.

\section{Materials and Methods}

В науке выделяются четыре вида причины уклонения от налога: моральная, политическая, экономическая и техническая [2, с.453]. Общая суть моральной причины ухода от налога состоит в том, что большинство плательщиков оправдывают себя противостоянием налогу, обосновывая это непомерными, по их мнению, тяжелыми налоговыми обязанностями. Зачастую общественная потребность, реализуемая государством через финансирование из бюджета, которые формируются за счет налога, не осознается плательщиком в качестве объективной реальности.

К политической причине уходов от налога следует отнести тенденцию по лоббированию расхода в процессе определения направления экономической политики.

Экономическая причина выступает выгодой, получаемой налогоплательщиками в процессе избежание налога. Техническая причина уходов от налога кроется в запутанности и является сложным национальным налоговым законодательством.

Технические сложности налогообложения, расчеты налога позволяет плательщикам избегать платежи, не нарушив вместе с тем законы. Таким образом, причины уходов от налога большинство, но независимо от их форм, необходимо обеспечить противостояние неуплатам причитающиеся государствам налогового платежа, и в этом великим считается значение государственного налогового регулирования что подразумевает контроль. Необходимо подчеркнуть, что для организации налогового контроля важно базирование на принцип, представляющего собой базовое положение, которое определяет эффективную реализацию налогового контроля [6].

Принципом законности выступает в общем виде тот принцип? который обеспечивает строгость соблюдение предписания законодательного акта и основывается на предписаниях иного правового акта. Другими словами, любое действие в сфере налогового контроля обязано быть базированным на действующем законе.

Принцип юридического равенства выступает элементом связывающим налогообложение с налогом и сбором, не имеющим дискриминационный характер и применяющимся по социальным, рассовым, национальным, религиозным и иным подобным критериям.

В изучении принципа соблюдения прав человека и гражданина является важным обратить внимание на то, что права и свободы человека, в соответствии с Конституцией Кыргызской Республики, выступают наивысшими ценностями, орган и лицо, уполномоченное осуществлять налоговый контроль, обязано корректно и внимательно осуществлять свои функции по отношению налогоплательщику, при этом не унизив его честь и достоинство.

Принцип гласности раскрывает открытые и доступные для организации и гражданина формы деятельности государственного органа, а также процесс получения информации.

Под принципом ответственности понимается состояние лица, совершившего правонарушение, которому применяется мера юридической ответственности. В процессе налогового контроля происходят установления и документальная фиксация правонарушения в документе налогового контроля.

Принцип защиты прав заключается в защите прав субъектов посредством гарантирования на всех этапах развития налогового отношения, в частности и при осуществлении мероприятий 


\begin{tabular}{|c|c|c|c|c|c|c|}
\hline \multirow{4}{*}{ Impact Factor: } & ISRA (India) & $=3.117$ & SIS (USA) & $=0.912$ & ICV (Poland) & $=6.630$ \\
\hline & ISI (Dubai, UAE & $=0.829$ & РИНЦ (Russia) & $=0.156$ & PIF (India) & $=1.940$ \\
\hline & GIF (Australia) & $=0.564$ & ESJI (KZ) & $=5.015$ & IBI (India) & $=4.260$ \\
\hline & JIF & $=1.500$ & SJIF (Morocco) & $=5.667$ & OAJI (USA) & $=0.350$ \\
\hline
\end{tabular}

налогового регулирования. Контролируемый субъект может обжаловать действие и акт налогового органа на всех стадиях проведения контрольной деятельности [9]. В реализации принципы защиты права проверяемых организаций или физических лиц в процессе осуществления налогового контроля предполагается также права соответствующих объектов не исполнять неправомерное требование должностного лица или уполномоченного органа. Вместе с общеправовыми принципами налогового контролю невозможно не обратить внимание на принципы, которые традиционно выделяются учеными в процессе исследования контрольной деятельности как об особом виде управленческой деятельности.

Принцип независимости. Римской декларацией руководящих принципов контроля устанавливается, что контрольный орган может выполнять возложенную задачу в объективном плане эффективно лишь в случае, если они будут независимыми от проверяемой им организации и защищен от посторонних влияний [3, с.13-15]. Хотя государственный орган не бывает абсолютно независим, так как он составляет часть государства в целом, и высшим контрольным органам должны быть присущи признаки функциональной и организационной независимости, которая необходима для выполнения возложенного на них задачи.

Принцип планомерности. Данным принципом подразумевается, что любые виды контрольной деятельности, для которых характерны их постадийная реализация, должны быть тщательно подготовлены и распланированы по конкретной временной рамке [7]. Другими словами мероприятие налогового контроля соответствующим образом подготавливается, устанавливается срок и очередность проверки того или иного субъекта хозяйствования.

Регулярность (систематичность) контроля как принцип имеет цикличный характер, где некоторый действия могут повторяться через определенный промежуток времени.

Принципы объективности и достоверности. Принципы объективности и достоверности результата налогового контроля подразумевает, что решения руководителей уполномоченных органов должны соответствовать фактически существующему обстоятельству, выявленному в ходе реализации мероприятия налогового контроля, и включать в себя выводы о соответствиях/несоответствиях налоговому законодательству совершенного налогоплательщиком действия [8].

Под принципом документального оформления результата контроля рассматривается, что в процессе осуществления мероприятия налогового контроля любой обнаруженный факт, действие и событие должен фиксироваться в документе установленного вида и формы с обязательным наличием соответствующего реквизита.

Роль принципа взаимодействия и обмена данными с другим государственным органом, как правило, важна в ходе реализации результата контрольной деятельности, особенно в том случае, если выявлено нарушение законодательства, контролирующими органами необходимо обращаться к другому государственному органу, который имеет соответствующее полномочие по применению меры ответственности.

Следует подчеркнуть, что перечисленные выше принципы общеправового характера и принципы контрольной направленности не могут исчерпывать систему принципов налогового контроля, вместе с тем они составляют основу при их организации [10]. Налоговый контроль реализуется посредством осуществления следующих основных направлений: ведения учета организации и физического лица; осуществление налогового контроля за своевременностью уплат налога и сбора; осуществление налогового контроля за правильностью исчислений и полнотой уплат суммы налога и сбора, за надлежащим учетом дохода, расхода и объекта налогообложения; осуществление налогового контроля за законностью использования налоговой льготы; осуществление налогового контроля за своевременностью и правильностью удержаний сумм налога налоговым агентом; осуществление налогового контроля за соответствием крупного расхода физического лица его доходам; осуществление налогового контроля за своевременностью перечислений налогового платежа; осуществление налогового контроля за правомерностью возмещений суммы косвенного налога из бюджета.

Деятельность органов государства по осуществлению налоговый контроль отличается большим разнообразием и затрагивает все стороны налогового производства. Создание определяемых нормами права режимных условий, вести учет налогоплательщиков, объектов налогообложения, начисленных и уплаченных налогов - вся эта деятельность протекает в рамках налоговых правоотношений [4, c.119].

\section{Conclusion}

Таким образом, налоговый контроль занимает весьма значительное место в системе государственного финансового контроля, поскольку посредством осуществления контрольных функцй государственными 


\begin{tabular}{|c|c|c|c|c|c|c|}
\hline \multirow{4}{*}{ Impact Factor: } & ISRA (India) & $=3.117$ & SIS (USA) & $=0.912$ & ICV (Poland) & $=6.630$ \\
\hline & ISI (Dubai, UAE & $=0.829$ & РИНЦ (Russia & $=0.156$ & PIF (India) & $=1.940$ \\
\hline & GIF (Australia) & $=0.564$ & ESJI (KZ) & $=5.015$ & IBI (India) & $=4.260$ \\
\hline & JIF & $=1.500$ & SJIF (Morocco & $=5.667$ & OAJI (USA) & $=0.350$ \\
\hline
\end{tabular}

налоговыми органами обеспечивается не только соблюдение налогового законодательства, но и непосредственное привлечение финансовых ресурсов в государственный бюджет. Здесь очевидна большая роль налогового контроля в обеспечении исполнения бюджета государства по доходам, поскольку 80-90\% бюджетных доходов страны базируется на налоговых поступлениях [5]. Без эффективной работы налоговых органов в области контроля невозможно выполнение государством своих непосредственных функций.

Таким образом, налоговый контроль занимает значительное место и играет важную роль во всей системе финансового контроля.

\section{References:}

1. Birimkulova, K. D. (2012). Nalogovaya sistema Kyirgyizskoy Respubliki. uchebnoe posobie. (p.365). B.: Nur-AS.

2. Gracheva, V. Y. (2000). Problemyi pravovogo regulirovaniya gosudarstvennogo finansovogo kontrolya. (p.453). M.: Yurisprudentsiya.

3. Novoselov, K. V. (2008). Printsipyi i praktika nalogovogo kontrolya organizatsiy. Rossiyskiy nalogovyiy kurer, № 11, 13-15.

4. Amanaliev, U. O. (2016). Perspektivyi unifikatsii nalogovogo prava Kyirgyizskoy Respubliki. Ekonomika i parvo. Zhurnal nauchnyiy statey \#4, aprel, Moskva, 119.

5. Koychuev, T. K. (1995). Ekonomika perehodnogo perioda: uchebnoe posobie. B.: Ilim.
6. Kucherov, I. I., Sudakov, O. Y., \& Oreshkin, I. A. (2001). Nalogovyiy kontrol $i$ otvetstvennost za narusheniya zakonodatelstva o nalogah $i$ sborah. Moscow.

7. (2001). Nalogovoe parvo. Uchebnik. In N. A. Shevelevoy (Eds). Moscow.

8. Rodionov, I. B. (n.d.). Teoriya sistem $i$ sistemnyiy analiz: kurs lektsiy. Retrieved 2019, from http://victor-safronov.narod.ru/systemsanalysis/lectures/rodionov.html

9. Abramchik, J. Y. (2005). Nalogovoe administrirovanie $\mathrm{v}$ sisteme finansovogo kontrolya. Finansovoe parvo, \# 6, Elektronnyiy resurs. Dostup iz sprav. -pravovoy sistemyi «KonsultantPlyus».

10. Gorlenko, I. I. (2003). Formyi provedeniya nalogovogo kontrolya. Nalogovyiy vestnik, № 3. 